\title{
Evaluation of Quality of Chia (Salvia hispanica), Sesame (Sesamum indicum), and Quinoa (Chenopodium quinoa) Oils
}

\author{
Maria Paula Fortuna Clara ${ }^{1}$ \\ https://orcid.org/0000-0001-9740-5976
}

\section{Carolina Médici Veronezi ${ }^{1^{\star}}$}

https://orcid.org/0000-0001-9737-6933

\author{
Neuza Jorge ${ }^{1}$ \\ https://orcid.org/0000-0001-7166-0880
}

'São Paulo State University, Department of Food Engineering and Technology, São José do Rio Preto, São Paulo, Brazil.

Received: 2019.06.03; Accepted: 2020.02.07.

${ }^{*}$ Correspondence: cveronezi@hotmail.com; Tel.: +55 17992000822 (C. M. V.)

\section{HIGHLIGHTS}

- Chia oil showed the greatest degradation.

- Sesame oils stood out for the highest of monounsaturated fatty acids, and bioactive compounds

- The oils studied have potential use in the formulation of new products

\begin{abstract}
Each year, the consumption of vegetable oils increases gradually. Some oils, such as chia, sesame, and quinoa, are consumed due to the nutritional properties and health promoters that have been recognized in their components. Based on this premise, the present study aimed to characterize chia (Salvia hispanica), sesame (Sesamum inducum), and quinoa (Chenopodium quinoa) oils, in order to enable their applications in the development of new food products. Chia oil presented higher degradation, as it stood out with higher amounts of free fatty acids (4.46\%) and peroxide value $(18.35 \mathrm{meg} / \mathrm{kg})$. It is an oil that is rich in polyunsaturated fatty acids $(75.47 \%)$, and, consequently, with high refractive index $(1,475)$ and iodine value $(192.86 \mathrm{~g} / 100 \mathrm{~g})$. Quinoa oil stood out for its higher oxidative stability $(17.55 \mathrm{~h})$ and higher amount of phenolic compounds $(190.84 \mathrm{mg} / 100 \mathrm{~g})$. Sesame and quinoa oils showed no significant difference for carotenoids, but sesame oil had higher content of total tocopherols $(656.50 \mathrm{mg} / \mathrm{kg})$. Thus, the oils can be used in technological processes and/ or in the formulation of new food products, in order to their increase the nutritional value.
\end{abstract}

Keywords: special oils; physicochemical properties; bioactive compounds.

\section{INTRODUCTION}

Oils play a key role in human nutrition, act as a vehicle for fat-soluble vitamins, provide energy[1], impart nutritional value, taste, texture, aroma, and palatability to food, act as a heat transfer medium during the frying process, and provide consistency and specific fusion characteristics to the products containing them [2]. Oils are products obtained from vegetable species consisting of approximately 95\% triacylglycerols and 2-5\% non-glyceride compounds (phospholipids, carbohydrate traces, methyl ketones, 
free fatty, acids and fatty acid degradation products). In the unsaponifiable fraction, there are substances beneficial to the organism, such as tocopherols, phenolic compounds, phytosterols, and carotenoids, called bioactive compounds [3].

The taste, nutritional value and physicochemical properties of vegetable oils depend not only on the raw material, but also on the extraction method [4]. The most commonly used extraction methods are solvent extraction or cold pressing. During solvent extraction, essential nutrients and bioactive compounds are degraded, as there is interference of temperature. It is, however, an efficient method [5]. On the other hand, cold pressing is a fast, easy, and inexpensive method in which oils retain high levels of bioactive phytochemicals, especially antioxidants, which can add greater nutritional value to processed foods [6]. Studies have shown that some components of the oils extracted by cold pressing reinforce the immune system and suppress anti-inflammatory disorders [7].

As consumers are increasingly aware of the relation between diet, health, and wellness resulting from choices in foods that are considered healthier and more nutritious, it is important to study special oils, due to the nutritional properties and health promoters that have been recognized in some of their components [8]. In this context, the evaluation of chia, sesame, and quinoa oils, obtained by cold pressing, becomes important, in order to make feasible their use in the development of new food products.

\section{MATERIAL AND METHODS}

\section{Oils}

Chia, sesame, and quinoa oils were supplied by industries located in the South (Panambi, Rio Grande do Sul) and Southeast (São Paulo, São Paulo) regions of Brazil, and stored at $-18^{\circ} \mathrm{C}$. The grains used in the process were produced by the company itself or in conjunction with committed producers, and the oils were obtained by cold pressing.

\section{Physicochemical properties}

Standard AOCS methods [9] were used to free fatty acids, peroxide value, conjugated dienoic acid, saponification, iodine value, and refractive index. Oxidative stability was performed on Rancimat (model 743 , Metrohm Ltd., Herisau, Switzerland) at $110^{\circ} \mathrm{C}$ and $20 \mathrm{~L} / \mathrm{h}$ air flow, and the induction period expressed in hours, according to AOCS [9].

For fatty acid composition analysis, first the oils were esterifited, using methanolic $\mathrm{KOH}$ following the AOCS [9] method. The samples were injected into a gas chromatography (model 3900, Varian, Walnut Creek, CA, USA) equipped with a flame ionization detector, split injection system and capillary column (CPSil 88, Microsorb, $50 \mathrm{~m} \times 0.25 \mathrm{~mm}$, film thickness: $0.25 \mathrm{~mm}$ internal diameter) were used. Column temperature was set as $90{ }^{\circ} \mathrm{C}$ for $10 \mathrm{~min}$, followed by an increment of $10^{\circ} \mathrm{C} / \mathrm{min}$. until reached $195{ }^{\circ} \mathrm{C}$ where it was held for $16 \mathrm{~min}$. The temperatures used in the injector and detector were 230 and $250{ }^{\circ} \mathrm{C}$, respectively. The carrier gas was hydrogen with linear velocity of $30 \mathrm{~mL} / \mathrm{min}$. The identification of fatty acid methyl esters was done through the comparison of the retention time for samples and purity standards between 99.1 and $99.9 \%$ (Supelco, Bellefonte, USA), and the results were expressed in \%. The composition of triacylglycerols was obtained by random distribution using a computer program based on the fatty acid profile [10].

Carotenoid quantification was performed using a scanning spectrophotometer (model UV-VIS mini 1240, Shimadzu, Chiyoda-ku, Tokyo, Japan), with a wavelength range of 300 to $550 \mathrm{~nm}$, according to the method proposed by Rodriguez-Amaya [11], and expressed in $\mu \mathrm{g} / \mathrm{g}$.

The total phenolic content were extracted according to the method proposed by Parry and coauthors [12] and quantified with Spectrophotometer (UV-VIS mini 1240, Shimadzu, Chiyoda-ku, Tokyo, Japan), using Folin-Ciocalteu reagent as described by Singleton and Rossi [13]. Gallic acid standard curve was construted $(R 2=0.9999)$, and used to evaluated the total phenolics, with were expressed as $\mathrm{mg} E A G / \mathrm{kg}$.

The tocopherol contents were performed using high performance liquid chromatography by the AOCS method [9]. A high-performance liquid chromatograph (model 210-263, Varian Inc., Walnut Creek, CA, USA), equipped with a fluorescence detector the mobile phase was composed of $n$-hexane: isopropyl alcohol (99.5: $0.5 \mathrm{v} / \mathrm{v}$ ) and $1.2 \mathrm{~mL} / \mathrm{min}$ flow. The quantification of each ibsomer was performed by external standardization based on peak areas using $\alpha-, \beta-, \gamma^{-}$and $\delta$-tocopherol standards (Supelco, Bellefonte, Pennsylvania, USA) and expressed as $\mathrm{mg} / \mathrm{kg}$ of oil. 


\section{Statistical analysis}

The obtained data were analyzed using analysis of variance and the differences between the averages were tested at $5 \%$ probability by Tukey test [14], through the ESTAT program, version 2.0.

\section{RESULTS AND DISCUSSION}

Chia oil presented higher quantities of free fatty acids $(4.46 \%)$ and peroxide $(18.35 \mathrm{meg} / \mathrm{kg})$ value. These values are higher than the limits established by the Codex Alimentarius Commission[15] for cold pressed oils (Table 1). The hydrolytic and oxidative degradations of chia oil may be due to high the content of unsaturated fatty acids, mainly linolenic[16]. Besides that, chia seeds have a high amount of soluble fibers, which help stabilize the structure of food products, such as dispersions and emulsions through gel formation or continuous phase thickening, causing great water retention capacity, and, consequently, higher humidity[17].

Table 1. Physicochemical properties of oils.

\begin{tabular}{ccccc}
\hline Determinations & Chia & Sesame & Quinoa & Codex $^{15}$ \\
\hline Free fatty acids $(\%$ oleic) & $4.46 \pm 0.02^{\mathrm{a}}$ & $1.73 \pm 0.03^{\mathrm{b}}$ & $0.57 \pm 0.01^{\mathrm{c}}$ & Max. 2 \\
Peroxide value (meq/kg) & $18.35 \pm 1.63^{\mathrm{a}}$ & $13.05 \pm 0.69^{\mathrm{b}}$ & $2.71 \pm 0.11^{\mathrm{c}}$ & Max. 15 \\
Conjugated dienoic acids $(\%)$ & $0.32 \pm 0.00^{\mathrm{b}}$ & $0.37 \pm 0.00^{\mathrm{a}}$ & $0.22 \pm 0.01^{\mathrm{c}}$ & - \\
Refractive index $\left(40^{\circ} \mathrm{C}\right)$ & $1.475 \pm 0.05^{\mathrm{a}}$ & $1.468 \pm 0.029^{\mathrm{c}}$ & $1.470 \pm 0.05^{\mathrm{b}}$ & $*$ \\
lodine value $(\mathrm{g} / 100 \mathrm{~g})$ & $192.86 \pm 0.01^{\mathrm{a}}$ & $112.27 \pm 0.05^{\mathrm{b}}$ & $98.87 \pm 0.01^{\mathrm{c}}$ & $*$ \\
Saponification value $(\mathrm{mg} / \mathrm{g})$ & $193.87 \pm 0.02^{\mathrm{a}}$ & $192.03 \pm 0.01^{\mathrm{b}}$ & $191.55 \pm 0.03^{\mathrm{c}}$ & $*$ \\
Oxidative stability $(\mathrm{h})^{* *}$ & $0.50 \pm 0.04^{\mathrm{c}}$ & $3.89 \pm 0.02^{\mathrm{b}}$ & $17.55 \pm 0.04^{\mathrm{a}}$ & - \\
\hline
\end{tabular}

Means \pm standard deviations of the analyzes followed by the same letters in the lines do not differ by the Tukey test (p>0.05). ${ }^{*}$ Its depends on the oil. ${ }^{* *}$ Performed on Rancimat (model 743, Metrohm Ltd., Herisau, Switzerland) at $110^{\circ} \mathrm{C}$ and $20 \mathrm{~L} / \mathrm{h}$ air flow

The amount of conjugated dienoic acids is proportional to the absorption of oxygen and the formation of peroxides during the initial stages of oxidation[18]. Therefore, it can be inferred that sesame oil obtained higher absorption, since it presented $0.37 \%$

Chia oil presented higher refractive index (1.475) and iodine value (192.86 g/100 g), which may be related to the concentration of polyunsaturated fatty acids, particularly linolenic and linoleic acids. Timilsena and coauthors [19] and Ixtaina and coauthors [20], when analyzing the physicochemical properties of chia oil, obtained higher iodine values, $208.5-209.4$ and $204 \mathrm{~g} / 100 \mathrm{~g}$, respectively. These authors came to the conclusion that just as the refractive index, the iodine value is related to the concentrations of polyunsaturated fatty acids, such as linolenic and linoleic. Different results can occur due to the different varieties, the processing and types of thermal treatments to which the oils were subjected.

Chia oil presented higher saponification value $(193.87 \mathrm{mg} \mathrm{KOH} / \mathrm{g})$. Thus, it can be inferred that this oil is composed of larger amounts of short chain fatty acids, corroborating with Ixtaina and coauthors [20] when characterizing the chia oil extracted by different methods. The oxidative stability of the oils during and after processing is one of the most important characteristics, both in technological and nutritional aspects, since it can be influenced by the composition of fatty acids and the presence of natural antioxidant compounds [21]. Quinoa oil showed the highest oxidative stability (17.55 h), while chia oil showed only 0.55 $\mathrm{h}$. This difference is due to the presence of natural antioxidant compounds in quinoa oil and the polyunsaturated fatty acid composition of chia oil.

When analyzing the fatty acid profile (Table 2), it was observed that among the saturated fatty acids, palmitic acid stood out in higher quantities in chia (6.18\%), and sesame (7.14\%) oils, while stearic acid stood out in quinoa oil with $5.6 \%$. 
Table 2.Profile fatty acids of oils.

\begin{tabular}{cccc}
\hline Fatty acids (\%) & Chia & Sesame & Quinoa \\
\hline Palmític (C16:0) & $6.18 \pm 0.02^{\mathrm{b}}$ & $7.14 \pm 0.02^{\mathrm{a}}$ & $3.57 \pm 0.02^{\mathrm{c}}$ \\
Stearic (C18:0) & $3.82 \pm 0.02^{\mathrm{c}}$ & $5.30 \pm 0.03^{\mathrm{b}}$ & $5.60 \pm 0.02^{\mathrm{a}}$ \\
Oleic (C18:1n9c) & $13.88 \pm 0.01^{\mathrm{c}}$ & $60.19 \pm 0.02^{\mathrm{a}}$ & $51.11 \pm 0.01^{\mathrm{b}}$ \\
Linoleic (C18:2n6c) & $18.66 \pm 0.02^{\mathrm{c}}$ & $26.68 \pm 0.03^{\mathrm{b}}$ & $39.3 \pm 0.02^{\mathrm{a}}$ \\
Linolenic (C18:3n3c) & $56.81 \pm 0.01^{\mathrm{a}}$ & $0.35 \pm 0.01^{\mathrm{b}}$ & $0.10 \pm 0.01^{\mathrm{c}}$ \\
Arachidonic (C20:0) & $0.67 \pm 0.01^{\mathrm{a}}$ & $0.36 \pm 0.01^{\mathrm{b}}$ & $0.34 \pm 0.01^{\mathrm{b}}$ \\
Saturated & $10.66 \pm 0.01^{\mathrm{b}}$ & $12.79 \pm 0.01^{\mathrm{a}}$ & $9.50 \pm 0.01^{\mathrm{c}}$ \\
Monounsaturated & $13.88 \pm 0.01^{\mathrm{c}}$ & $60.19 \pm 0.02^{\mathrm{a}}$ & $51.11 \pm 0.01^{\mathrm{b}}$ \\
Polyunsaturated & $75.47 \pm 0.01^{\mathrm{a}}$ & $27.03 \pm 0.04^{\mathrm{c}}$ & $39.40 \pm 0.01^{\mathrm{b}}$ \\
\hline
\end{tabular}

Means \pm standard deviations of the analyzes followed by the same letters in the lines do not differ by the Tukey test (p>0.05).

Sesame oil obtained the highest amount of oleic acid (60.19\%), results highter than found by Ozcan and coauthors [22] and Mohammed and coauthors [23]. According to Zheljazkov and coauthors [24], the oils can be classified in relation to the amount of oleic fatty acid, as traditional (14-39\%), mid oleic (42-72\%) and high oleic (75-91\%). Thus, sesame and quinoa oils may be considered mid oleic. From the nutritional point of view it is very important, since there is evidence that this fatty acid can maximize the levels of the high density lipoprotein cholesterol fraction[25].

In relation to polyunsaturated fatty acids, chia stood out with higher content of linolenic acid (56.81\%). When evaluating the fatty acid composition of chia oils, Bodoira and coauthors [26] and Ozcan and coauthors [27] obtained values very close to those found in this study. Although the fatty acid composition of this oil is favorable from the nutritional point of view, it presents a great technological disadvantage due to its low oxidative stability[28].

Differences observed in fatty acid composition of oils can be attributed to several factors such as the variation in climatic conditions, cultivation locations, agronomic practices, and genetic backgrounds of seeds, as well as esterification and analysis methods[27].

Based on the fatty acids, the triacylglycerols profile was obtained, as shown in Table 3. Chia oil is the only one with triacylglycerols composed of linolenic acid (AI), with higher amounts of AIAIAI (19.1\%) and LAIAI (18.7\%). Ixtaina and coauthors [20], characterizing chia oil extracted by different methods, also found high amounts of these two triacylglycerols. On the other hand POS, POO, SOO and $\mathrm{OOO}$ triacylglycerols are present only in sesame and quinoa oils, possibly due to high percentage of oleic acid. 
Table 3. Profile triacylglycerols of oils.

\begin{tabular}{lccc}
\hline $\begin{array}{l}\text { Triacylglycerols } \\
\text { (\%) }\end{array}$ & Chia & Sesame & Quinoa \\
\hline POS (C52:1) & - & 1.4 & 0.6 \\
POO (C52:2) & - & 7.9 & 2.9 \\
PLO (C52:3) & 1.0 & 7.1 & 4.5 \\
PLL (C52:4) & 0.7 & 1.6 & 1.7 \\
PAIO (C52:4) & 3.1 & - & - \\
PAIL (C52:5) & 4.1 & - & - \\
PAIAI (C52:6) & 6.2 & - & - \\
SOO (C54:2) & - & 5.9 & 4.5 \\
SLO (C54:3) & 0.6 & 5.3 & 6.9 \\
OOO (C54:3) & - & 22.5 & 13.7 \\
OLO (C54:4) & 1.1 & 29.9 & 31.7 \\
OLL (C54:5) & 1.5 & 13.3 & 24.4 \\
SAIL (C54:5) & 2.5 & - & - \\
OAIO (C54:5) & 3.4 & - & - \\
LLL (C54:6) & 0.7 & 1.9 & 6.3 \\
SAIAI (C54:6) & 3.8 & - & - \\
OAIL (C54:6) & 9.2 & - & - \\
LAIL (C54:7) & 6.2 & - & - \\
OAIAl (C54:7) & 14.0 & - & - \\
LAIAI (C54:8) & 18.7 & - & - \\
AIAIAI (C54:9) & 19.1 & - & - \\
Others & 4.1 & 3.2 & 2.7 \\
\hline
\end{tabular}

P (palmític), O (oleic), L (linoleic), S (Stearic), and Al (linolenic).

Table 4 shows that chia oil presents a lower amount of total carotenoids (5.03 $\mu \mathrm{g} \beta$-carotene/g) than the others. Ixtaina and coauthors [20], when characterizing chia oils found lower contents $(0.58-1.21 \mu \mathrm{g} \beta$ carotene/g), whereas, Bodoira and coauthors [26], when evaluating the stability of chia oil and the effect of natural antioxidants, obtained levels, $5.41 \mu \mathrm{g} \beta$-carotene $/ \mathrm{g}$ close, to those found in this study. The authors further reported that, when considering the fatty acid composition of chia oil, it can be understood that the contents of carotenoids presented do not have sufficient antioxidant action to provide protection against photooxidative degradation.

Regarding phenolic compounds, quinoa oil presented high amount (190.84 mg/kg). However, Multari and coauthors [29] evaluated the effect of different drying temperatures on quinoa grains and found 293$994 \mathrm{mg} / \mathrm{kg}$ of phenolic compounds, showing that temperatures of 60 and $70{ }^{\circ} \mathrm{C}$ facilitated their extraction.

The divergence of values between phenolic compounds can be attributed to several factors, such as the binding of polyphenols to other substances, changes in the chemical structure of polyphenols that could not be determined by the available methods, the reactivity of Folin-Ciocalteu reagent with other compounds. and in the oil extraction method[30]. Ozcan and coauthors [31] found that there is a greater amount of phenolic compounds in oil extracted by the Soxhlet method compared to the cold press, suggesting the potential enhancer of the Soxhlet method in the phenolic profile of chia oil.

Table 4. Bioactive compounds of oils.

\begin{tabular}{lccc}
\hline Determinations & Chia & Sesame & Quinoa \\
\hline Carotenoids $(\mu \mathrm{g} \beta$-carotene/g) & $5.03 \pm 0.13^{\mathrm{b}}$ & $19.46 \pm 0.13^{\mathrm{a}}$ & $17.39 \pm 0.94^{\mathrm{a}}$ \\
Phenolic compounds $(\mathrm{mg} / \mathrm{kg})$ & $131.10 \pm 4.09^{\mathrm{b}}$ & $88.73 \pm 4.47^{\mathrm{c}}$ & $190.84 \pm 5.21^{\mathrm{a}}$ \\
Tocopherols $(\mathrm{mg} / \mathrm{kg})$ & & & \\
$\quad$ & & & \\
$\quad$-tocol & $13.30 \pm 0.06^{\mathrm{c}}$ & $216.38 \pm 0.14^{\mathrm{a}}$ & $26.51 \pm 0.03^{\mathrm{b}}$ \\
$\quad$-tocol & $88.61 \pm 0.04^{\mathrm{c}}$ & $440.12 \pm 0.10^{\mathrm{a}}$ & $213.07 \pm 0.11^{\mathrm{b}}$ \\
$\quad$-tocol & nd & nd & $103.90 \pm 0.14$ \\
$\quad$ Totals & $101.91 \pm 0.01^{\mathrm{c}}$ & $656.50 \pm 0.24^{\mathrm{a}}$ & $343.48 \pm 0.28^{\mathrm{b}}$
\end{tabular}

Means \pm standard deviations of the analyzes followed by the same letters in the lines do not differ by the Tukey test $(p>0.05)$. nd: not detected (limits of detection: $\alpha$-tocol $\leq 3.15 \mathrm{mg} / \mathrm{kg}, \gamma$-tocol $\leq 8.65 \mathrm{mg} / \mathrm{kg}$, $\delta$-tocol $\leq 2.30 \mathrm{mg} / \mathrm{kg}$ ). 
The importance of tocopherols present in vegetable oils is related to their antioxidant properties in animal and vegetable tissues and physiological functions [32]. Chia oil presented the lowest levels of $\alpha$ tocopherol $(13.3 \mathrm{mg} / \mathrm{kg})$ and $\mathrm{y}$-tocopherol $(88.61 \mathrm{mg} / \mathrm{kg})$, showing that it is not technologically stable. In the sesame oil, higher amount of total tocopherols was found $y$-tocopherol having stood out with $67 \%$ of this total. Therefore, this oil can be considered a good source of tocopherols.

Only in quinoa oil was $\delta$-tocopherol found and in a quantity $(103.90 \mathrm{mg} / \mathrm{kg})$ higher than what found by Przygada and Wejnerowska[33] when studying quinoa oil extracted by supercritical fluid with different combinations of temperature, pressure and time. This tocopherol isomer has high antioxidant capacity, which, when correlated to the fatty acid profile, can impart high oxidative stability to the oil [34].

\section{CONCLUSION}

The physicochemical properties of the oils, especially the low values of free fatty acids, peroxides and dienoic acids, showed that quinoa oil has better quality than the others, besides high oxidative stability, since it is a mid oleic oil and presents $\delta$-tocopherol, which has high antioxidant potential. In contrast, sesame oil had higher amounts of monounsaturated fatty acids, carotenoids and total tocopherols. In conclusion, the oils studied have potential use in the formulation of new products, to enrich them nutritionally, or to be mixed with others that contain low levels of bioactive compounds, thus increasing health benefits.

Funding: This research received no external funding.

Acknowledgments: The authors would like to thank the National Council of Scientific and Technological Development $(\mathrm{CNPq})$, for sponsoring the productivity and the Coordination of Improvement of Higher Education Personnel (CAPES), for sponsoring the research

Conflicts of Interest: The authors declare no conflict of interest.

\section{REFERENCES}

1. Gibson M, Newsham P. Lipids, oils, fats, and extracts. In Food Science and the Culinary Arts; Gibson M, Eds.; Academic Press:London, 2018.

2. Rogers MA. Fat replacers. In Encyclopedia of Food Chemistry.Elsevier;Amsterdam, 2018.

3. Arranz S, Cert R, Pérez-Jiménez J, Cert A, Saura-Calixto F. Comparison between free radical scavenging capacity and oxidative stability of nut oils. Food Chem. 2008; 110:985-990.

4. Majchrzak T, Wojnowski W, Dymerski T, Gębicki J, Namieśnik J. Electronic noses in classification and quality control of edible oils: a review. Food Chem. 2018; 246:192-201.

5. Garcia A, Ruiz-Mendez MV, Romero C, Brenes M. Effect of refining on the phenolic composition of crude olive oils. J Am Oil Chem Soc. 2006; 83:159-164.

6. Ananth DA, Deviram G, Mahalakshmi V, Sivasudha T, Tietelm Z. Phytochemical composition and antioxidant characteristics of tradicional cold pressed seed oils in South India. Biocatalysis Agric Biotech. 2019, 17:416-421.

7. Ixtaina VY, Nolasco SM, Tomás MC. Physical properties of chia (Salvia hispanica L.) seeds. Ind Crops Prod. 2008, 28:286-293.

8. Oliveira-Alves SC, Vendramini-Costa DB, Cazarin CBB, Maróstica Júnior MR, Ferreira JPB, Silva AB, Prado MA, Bronze MR. Characterization of phenolic compounds in chia (Salvia hispanica L.) seeds, fiber flour and oil. Food Chem. 2017, 232:295-305.

9. AOCS. Official methods and recommended practices of the American Oil Chemists' Society. 6. ed. American Oil Chemists' Society: Champaing, 2009.

10.Antoniosi Filho NR, Mendes OL, Lanças FM. Computer prediction of triacylglycerol composition of vegetable oils by HRGC. Chromatogr. 1995, 40:557-562.

11.Rodriguez-Amaya DB. A guide to carotenoids analysis in food. ILSI Press: Washington, 2001.

12.Parry JW, Su L, Luther M, Zhou K, Yurawecz MP, Whittaker P, Yu L. Fatty acid composition and antioxidant properties of cold-pressed marionberry, boysenberry, red raspberry, and blueberry seed oils. J. Agric. Food Chem. 2005, 53:566-573.

13.Singleton VL, Rossi JA. Colorimetry of total phenolics with phosphomolybdic and phosphotungstic acid reagents. Am. J. Enol. Vitic. 1965,16:144-158.

14.Gacula JM, Singh J, Bi S. Statistical methods in food and consumer research. Academic Press:London, 2008.

15.Codex Alimentarius Commision. Codex-Stan 210: codex standard for named vegetable oils. Codex Alimentarius Commission: Rome, 2009. 
16. Martínez ML, Marín MA, Faller CMS, Revol J, Penci MC, Ribotta PD. Chia (Salvia hispanica L.) oil extraction: study of processing parameters. Food Sci Technol. 2012, 47:78-82.

17.Capitani MI, Spotorno V, Nolasco SM, Tomás MC. Physicochemical and functional characterization of by-products from chia (Salvia hispanica L.) seeds of Argentina. LWT - Food Sci Technol 2012, 45:94-102.

18.Shahidi F, Liyana-Pathirana CM, Wall DS. Antioxidant activity of white and black sesame seeds and their hull fractions. Food Chem. 2006, 99:478-483.

19.Timilsena YP, Vongsvivut J, Adhikari R, Adhikari B. Physicochemical and thermal characteristics of Australian chia seed oil. Food Chem. 2017, 228:394-402.

20.Ixtaina VY, Martínez ML, Spotorno V, Mateo CM, Maestri DM, Diehl BWK, Nolasco SM, Tomás MC. Characterization of chia seed oils obtained by pressing and solvent extraction. J Food Compost Anal. 2011, 24:166-174.

21. Franco D, Rodríguez-Amado I, Agregán R, Munekata PES, Vázquez JA, Barba FJ, Lorenzo JM. Optimization of antioxidants extraction from peanut skin to prevent oxidative processes during soybean oil storage. Food Sci Technol. 2018, 88:1-8.

22. Özcan MM, Endes Z, Er F. Physical and chemical properties of some seed and kernel oils. Asian J. Chem. 2010, 22:6531-6536.

23.Mohammed F, Abdulwali N, Guillaume D, Tenyang N, Ponka R, Al-Gadabi K, Bchitou R, Abdullah AH, Naji KM. Chemical composition and mineralogical residence of sesame oil from plants grown in different Yemeni environments. Microchemical J. 2018, 140:269-277.

24.Zheljazkov VD, Vick BA, Baldwin BS, Buehring N, Coker C. Oil productivity and composition of sunflower as a function of hybrid and planting date. Ind Crops Prod. 2010, 33:537-543.

25. Mba OI, Dumont MJ, Ngadi M. Palm oil: processing, characterization and utilization in the food industry - a review. Food Biosci. 2015, 10:26-41.

26. Bodoira RM, Penci MC, Ribotta PD, Martínez ML. Chia (Salvia hispanica L.) oil stability: study of the effect of natural antioxidants. Food Sci Technol. 2017, 75:107-113.

27. Ozcan MM, Al-Juhaimi FY, Ahmed IAM, Osman MA, Gassem MA. Effect of different microwave power setting on quality of chia seed oil obtained in a cold press. Food Chem. 2019, 278:190-196

28. Boskou D. Frying fats. CRC Press: Boca Raton, 2011.

29.Multari S, Marsol-Vall A, Keskitalo M, Yang B, Suomela JP. Effects of different drying temperatures on the content of phenolic compounds and carotenopids in quinoa seeds (Chenopodium quinoa) from Finland. J Food Comp Anal. 2018, 72:75-82.

30.Everette JD, Bryant QM, Green AM, Abbey YA, Wangila GW, Walker RB. Thorough study of reactivity of various compound classes toward the Folin-Ciocalteu reagent. J Agric Food Chem. 2010, 58:8139-8144.

31.Özcan MM, Al-Juhaimi FY, Ahmed IAM, Osman MA, Gassem MA. Effect of soxhlet and cold press extractions on the physico-chemical characteristics of roasted and non-roasted chia seed oils. J. Food Meas Charac. 2018, doi:10.1007/s11694-018-9977-z

32.Tang Y, Li X, Chen PX, Zhang B, Hernandez M, Zhang H, Marcone MF, Liu R, Tsao R. Characterisation of fatty acid, carotenoid, tocopherol/tocotrienol compositions and antioxidant activities in seeds of three Chenopodium quinoa Willd. Genotypes. Food Chem. 2015, 174:502-508.

33.Przygada K, Wejnerowska G. Extraction of tocopherol-enriched oils from quinoa seeds by supercritical fluid extraction. Ind Crops Prod. 2015, 63:41-47.

34. Isnardy $\mathrm{B}$, Wagner $\mathrm{KH}$, Elmadfa I. Effects of $\alpha-, \gamma^{-}$, and $\delta$ tocopherols on the autoxidation of purified rapeseed oil triacylglycerols in a system containing low oxygen. J Agric Food Chem. 2003, 51:7775-7780.

(C) 2020 by the authors. Submitted for possible open access publication under the terms and conditions of the Creative Commons Attribution (CC BY NC) license (https://creativecommons.org/licenses/by-nc/4.0/). 